\title{
Medical students perform basic life support skills in a simulated scenario better using a 4-stage teaching approach compared to conventional training
}

\author{
MAJA FRANGE ̌̌ ${ }^{1}$, MATEJ JENKO ${ }^{2}$, PRIMOŽ GRADIŠEK ${ }^{2,3}$, MIRT KAMENIK \\ 1 Simulation Center, Faculty of Medicine, University of Ljubljana, Ljubljana, Slovenia \\ 2 Clinical Department of Anesthesiology and Intensive Therapy, University Medical Center Ljubljana, Ljubljana, Slovenia \\ 3 Chair of Anesthesiology and Reanimatology, Faculty of Medicine, University of Ljubljana, Ljubljana, Slovenia \\ 4 Department of Anesthesiology, Intensive Care and Pain Management, University Medical Center Maribor, Maribor, Slovenia
}

Corresponding author: Maja Frangež

Simulation Center, Faculty of Medicine, University of Ljubljana

Viška cesta 53. SI-1000 Ljubljana, Slovenia

Phone: +38641838234

E-mail: maja.frangez@gmail.com

This work should be attributed to the Simulation Centre of the Faculty of Medicine, University of Ljubljana.

\section{ABSTRACT}

Introduction. Cardiopulmonary resuscitation is influenced by the quality of basic life support (BLS). The primary objective of our study was to compare efficiency in the acquisition of BLS skills using conventional training and the 4-stage approach as a teaching method for BLS training.

Methods. In a prospective, randomised, 2-parallel group study, 266 first year medical students were randomised to either conventional training or the 4-stage approach using 2000 and 2005 ERC (European Resuscitation Council) guidelines. The students were tested immediately after receiving training. Three ERC-certified instructors assessed BLS skills using video recordings.

Results. The students who were taught according to the 4-stage approach using 2000 guidelines preformed significantly better in the following steps: calls for help $(\mathrm{p}<0.01)$, opens the airway $(\mathrm{p}<0.01)$, places hands for chest compression correctly $(\mathrm{p}<0.01)$ and performs chest compressions correctly ( $<<0.01$ ), while using 2005 guidelines, only chest compression hand position improved significantly in the 4 -stage teaching group $(\mathrm{p}<0.01)$.

Conclusions. The 4-stage approach improved the efficiency of several steps of the BLS algorithm and the ability to follow the algorithm in the correct sequence using 2000 ERC guidelines, while in students using the 2005 ERC guidelines only chest compression hand position improved significantly. Students who were taught according to 2000 ERC guidelines had significantly better hand position than students who were taught according to
2005 guidelines, independent of teaching method used.

Key words: basic life support, medical students, education, teaching method

\section{INTRODUCTION}

Education in resuscitation is the critical link between knowledge, scientific progress, and survival of cardiac arrest patients. (1) The correct performance of basic life support is a critical step in the "Chain of survival", $(2,3)$ but several studies report poor CPR (cardiopulmonary resuscitation) quality, not only among laypeople, but also among health care professionals. $(3,4)$ A reason for this could be the complexity of steps, that include a greater number of psychomotor skills needed for effective CPR. $(6,7)$ Most people who complete CPR training will not perform effective basic CPR even immediately after training. (8)

All first year medical students at the Medical Faculty of Ljubljana are taught BLS (basic life support) as per current ERC (European Resuscitation Council) guidelines. In conventional training, instructors demonstrate BLS skills at a slow speed and provide a commentary. This is followed by students performing the skill under supervision. Conventional training or the "2-stage approach « was standard for decades but it has been shown that skills acquisition and retention after conventional training in CPR for laypeople are poor. (8-10) New models of teaching have been implemented at our faculty in order to improve the results of CPR performance.
One of them is the "4-stage approach", proposed by R. Peyton (Royal College of Surgeons) in 1998 (11-13) and adapted by Bullock for resuscitation courses in the United Kingdom. (14) In the 4-stage approach, the instructors first demonstrate the skill without commentary. Then they demonstrate the skill by breaking it into simple steps and provide commentary. In the third phase instructors demonstrate the skill and the student provides the commentary. In the final phase, the students demonstrate and comment on the skill procedure. (15)

Our study had two main objectives. The first was to compare efficiency in the acquisition of steps of the algorithm in conventional training and the 4-stage approach as a teaching method for BLS training among first year medical students using the 2000 and 2005 ERC guidelines. The second was to assess whether medical students follow the BLS algorithm in a correct sequence immediately after conventional training or the 4-stage approach using the 2005 ERC guidelines compared to the 2000 guidelines.

\section{MATERIALS AND METHODS}

\section{Trial design and participants}

This was a prospective, randomised, 2-parallel group study, conducted at the Simulation Centre of the Faculty of Medicine, University of Ljubljana in the academic year 2004/2005 and 2009/2010. The National Medical Ethics Committee of the Republic of Slovenia approved the study.

The study included 266 first-year medical 
students during their basic life support skills training course. They were informed about the study before the start of the course and they could choose not to participate.

\section{Intervention}

Students were randomly assigned to small teaching groups by random number generator (Microsoft Excel, Microsoft, Redmond, WA, USA) either to the 2-stage or the 4-stage teaching technique. 135 students participated in the academic year 2004/2005, 37 were taught the 4-stage teaching techniques and 98 the 2-stage teaching technique using 2000 ERC guidelines. 131 students participated in the academic year 2009/2010, 79 students were taught the 4-stage teaching technique and 52 students the 2 -stage teaching technique.

Students were randomised to either the 2-stage or the 4-stage teaching method. Teaching was performed by five instructors, skilled anaesthesiologists who had received training in university didactics, most of them were also European Resuscitation Council (ERC) instructors with experience in teaching skills using the 4 -stage teaching technique. The instructor had chosen a teaching technique before he was assigned to a group.

\section{Training}

At the beginning of the four and a half hour course, students listened to a onehour introductory lesson about the BLS algorithm. After the lesson, students received training either according to the conventional training method or the 4-stage teaching method, depending on randomisation. All students had a similar amount of time for supervised practice of skills and the course and demonstration for all groups took place at the same location with the same equipment.

\section{Outcomes}

After the course, each student individually entered a room with a fully clothed Laerdal Skillmaster Resusci Anne manikin on the floor and received the same instructions: "The person you see has suddenly collapsed. You are alone at the scene, please show me how you would proceed. The manikin that represents the patient is prepared for the demonstration «. The demonstration ended two minutes after the beginning of chest compressions.

BLS skills were assessed by three ERC-cer- tified instructors, independently of each other, using video recordings of students performing CPR. They were blinded to the teaching technique. All skills were judged visually. Results were obtained through a checklist with a different number of steps according to the algorithm (2000 or 2005 guidelines). For the comparison of the 2000 and 2005 guidelines we used only steps which are included in both guidelines. Each skill on the checklist was marked in two categories, pass or fail and was scored 1 or 0 respectively.

\section{Statistical analysis}

Data were analysed using The $\mathrm{R}$ project for statistical computing, version 3.2. with Logistic regression for repeated measures. Because logistic regression for repeated measures does not perform correctly when a low number of observations without an event need to be analysed, we used Fisher test in certain calculations. According to Bonferroni correction, the value of $\mathrm{p}<0.01$ was considered statistically significant.

\section{RESULTS}

The students who were taught according to the 4-stage approach, used in the 2000 guidelines, performed significantly better in the following steps: calls for help $(\mathrm{p}<0.01)$, opens the airway $(\mathrm{p}<0.01)$, correct chest compression hand placement $(p<0.01)$ and performs chest compressions correctly $(\mathrm{p}<0.01)$ (Table 1$)$. In the 2005 ERC guidelines group, only hand placement was significantly better $(p<0.01)$ (table 1). The 4-stage teaching group performed chest compression significantly better using the $2000(\mathrm{p}<0.01)$ and 2005 $(\mathrm{p}<0.00)$ ERC guidelines, in comparison to the 2-stage teaching group. However, students who were taught according to 2000 ERC guidelines had significantly better hand position than students who were taught according to 2005 guidelines, independent of the teaching method used (table 1).

Students followed the algorithm in the correct sequence significantly better using the 2000 ERC guidelines if they were taught with the 4-stage approach. The 4-stage approach does not improve the sequence of the algorithm using the 2005 ERC guidelines.

\section{DISCUSSION}

Comparison of both teaching techniques
The 2005 ERC guidelines were simplified with the aim to reduce the complexity of BLS skills. Some studies report improvements in outcome using newer guidelines but very little is known about the impact of simplification of the BLS algorithm and the different teaching method used for BLS training. $(16,17)$ No advantages of the 4-stage teaching technique have been reported, even in teaching complex skills, $(11,18)$ however two studies reported significant improvement when teaching complex skills. $(19,20)$ Our study showed that more steps of the algorithm were performed correctly if students were taught with the 4-stage approach using 2000 ERC guidelines, while in 2005 ERC guidelines only correct chest compression hand position was significantly improved in the 4-stage teaching group.

The 2000 ERC guidelines instruct rescuers to measure correct chest compression hand position relative to sternal and subcostal margins (»landmark " technique) (21) while in 2005 ERC guidelines this instruction is simplified. A study by Handley showed that there were shorter pauses between ventilations and compressions if the hands were simply positioned »in the centre of the chest ", as recommended in 2005 ERC guidelines. (22) In our study, incorrect hand position was significantly reduced using 2000 ERC guidelines compared to 2005 ERC guidelines, independent of the teaching method used. The reason for improved hand position in 2000 ERC guidelines could be more precise instructions that need more explanation. A study by Owen showed that simplifying chest compression position caused a significant increase in erroneous hand placement. (6) This is consistent with the results of our study. The effect of worsened hand position in the simplified technique is still unknown.

In this study, correct chest compression hand placement was significantly improved in the 4-stage teaching group using 2000 and 2005 ERC guidelines. We believe there are at least two reasons for these results. The first reason may lie with the instructors, who may have used more time to teach students correct hand position in the 4-stage teaching group. The second is the 4-stage teaching technique which provides more opportunities for reinforcing the skill. Chest compression hand placement is a complex process requiring more psychomotor skills, and according to Barelli and Scapigliati, the skills that involve mastery in cognitive, technical and process domains may well benefit from the 4-stage method of teaching; however, it is possible 
Table 1. Comparison of steps of basic life support algorithm in both teaching techniques using 2000 and 2005 ERC guidelines

\begin{tabular}{|c|c|c|c|c|c|c|c|c|}
\hline & 2000 & & & 2005 & & & & \\
\hline STEP & $\begin{array}{l}\text { 2-stage } \\
(\mathrm{N}=294) \\
\text { correctly }(\%)\end{array}$ & $\begin{array}{l}\text { 4-stage } \\
(\mathrm{N}=111) \\
\text { correctly (\%) }\end{array}$ & $\mathrm{p}$ value & $\begin{array}{l}2 \text {-stage } \\
(\mathrm{N}=156) \\
\text { correctly }(\%)\end{array}$ & $\begin{array}{l}\text { 4-stage } \\
(\mathrm{N}=234) \\
\text { correctly }(\%)\end{array}$ & P value & $\begin{array}{l}2 \text {-stage } \\
2000 / 2005 \\
\text { P value }\end{array}$ & $\begin{array}{l}4 \text {-stage } \\
2000 / \\
2005 \\
\text { P value }\end{array}$ \\
\hline $\begin{array}{l}\text { CHECKS UNRESPO- } \\
\text { SIVENESS }\end{array}$ & $278(94.6)$ & $111(100)$ & 0.48 (a) & $153(98.1)$ & $234(100)$ & $0.52(\mathrm{a})$ & 0.80 & 1 \\
\hline SHOUTS FOR HELP & $120(40.8)$ & $75(67.6)$ & $0.00^{*}$ & $119(76.3)$ & $195(88.3)$ & 0.57 & 0.80 & 0.44 \\
\hline OPENS AIRWAY & $140(47.6)$ & $99(89.2)$ & $0.00^{*}$ & $124(79.5)$ & $200(85.5)$ & 0.61 & $0.00^{*}$ & 0.93 \\
\hline ASSESSES BREATHING & $262(89.1)$ & $108(97.3)$ & 0.41 & $148(94.9)$ & $233(99.6)$ & 0.9 (a) & 0.482 & 0.81 \\
\hline $\begin{array}{l}\text { CALLS EMERGENCY } \\
\text { NUMBER }\end{array}$ & $191(65)$ & $107(96.4)$ & 0.36 & $102(65.4)$ & $191(81.6)$ & 0.41 & 0.99 & $0.00^{*}$ \\
\hline $\begin{array}{l}\text { CORRECTLY PER- } \\
\text { FORMS VENTILATION }\end{array}$ & $195(66.3)$ & $80(72.1)$ & 0.33 & $144(92.3)$ & $211(90.2)$ & 0.50 & $0.00^{*}$ & $0.00^{*}$ \\
\hline $\begin{array}{l}\text { CHEST COMPRESSION } \\
\text { HAND POSITION }\end{array}$ & $231(78.6)$ & $108(97.3)$ & $0.00^{*}$ & $40(25.6)$ & $119(50.9)$ & $0.00^{*}$ & $0.00^{*}$ & $0.00^{*}$ \\
\hline $\begin{array}{l}\text { CORRECT CHEST } \\
\text { COMPRESSION }\end{array}$ & $176(59.9)$ & $86(77.5)$ & $0.01^{*}$ & $116(74.4)$ & $172(73.5)$ & 0.84 & $0.01^{*}$ & 0.45 \\
\hline $\begin{array}{l}\text { COMBINES CHEST } \\
\text { COMPRESSION WITH } \\
\text { RESCUE BREATHS }\end{array}$ & $289(98.3)$ & $108(97.3)$ & 0.75 & $153(98.1)$ & $225(96.2)$ & 0.82 & 0.8 (a) & 0.45 \\
\hline $\begin{array}{l}\text { FOLLOWS ALGO- } \\
\text { RITHM IN CORRECT } \\
\text { SEQUENCE }\end{array}$ & $145(49.3)$ & $86(77.5)$ & $0.00^{*}$ & $105(67.3)$ & 207 (88.5) & 0.13 & $0.00^{*}$ & 0.24 \\
\hline
\end{tabular}

that this approach is not useful in skills that are too simple or too complex. (13) So the 4-stage teaching technique could be the way to improve chest compression hand placement.

Jenko et al. did not find any difference between the 4-stage and the 2-stage teaching technique in chest compression rate, depth of hand placement or incomplete release using 2005 ERC guidelines. (23) In our study, we found a difference in the number of correct hand positions. The reason for this may be in the method of assessment. In the cited study, the manikin report was used for comparison. In our study, video recordings were used, that might enable more detailed analysis. If the hands are not in the centre of the chest, it is sooner noted on the video recording than detected by the manikin sensors.

Our study suggests that the 4-stage teaching technique significantly improves skills performance in more complex 2000 ERC guidelines. This is consistent with other studies that suggest that more complex multidimensional tasks benefit the most from the 4-stage teaching technique. (19) The 2005 BLS guidelines contain fewer steps in the algorithm than 2000 BLS guidelines in order to try to improve acquisition of the BLS algorithm. In our study, results of simplification are twofold. At first, fewer steps are improved significantly using the 4-stage teaching technique in 2005 guidelines compared to 2000 guidelines. On the other hand, students improved several steps in the algorithm, even if they were taught the conventional way. In our study we found that students benefited from guideline simplification, with the exception of correct hand placement. Previous studies offered different results. For example, Owen et al. found no significant difference in the ability of healthcare students to perform steps in the correct order after training, using 2000 or more simplified 2005 ERC guidelines. (6)

\section{STUDY LIMITATIONS}

The sample size was quite large compared to similar studies $(24,25)$ but more than one instructor was included in each teaching technique. Teaching quality was unlikely to have varied within or between groups since all instructors were taught in accordance with ERC recommendations. The population observed in our study was medical students at the beginning of their first year and their knowledge was not very different from laypersons, but medi- cal students are well aware of the value of CPR skills in the early years of the medical curriculum and that they are potential first responders in a home environment or on clinical wards. (26)

The strong point of our study is that assessors were not included in the teaching process. They were all ERC - certified instructors and were blinded to the teaching technique used for each student. Video assessment gives the opportunity to see the recording more than once. Our study was prospective and comparable Laerdal manikins were used throughout the study. In our study we did not attempt to test longer term memory or skill retention.

\section{CONCLUSIONS}

The comparison of the two teaching techniques for BLS training showed that the 4-stage teaching approach significantly improves some segments of BLS performance immediately after BLS training among first year medical students. The difference is most obvious in more complex 2000 guidelines, where more steps in the algorithm were improved than in relatively simpler 2005 guidelines. More extended studies would be needed to determine 
the long-term effects of simplification of ERC guidelines and the impact of different teaching techniques. Further studies are required to compare ERC guidelines published in 2010 and newer guidelines in 2015.

\section{ACKNOWLEDGEMENT}

We are thankful to our colleagues, Aleksander Manohin, Doroteja Diallo Renko, Marjeta Verko, Dajna Buić Rerečić for their support and to the medical students in the BLS skills training course included in the study.

\section{REFERENCES}

1. Bottiger BW, Dirk B. Education. The link to survival. Notfall Rettungmedizin 2009;12 Suppl 2:24-5.

2. Lund I, Skulberg A. Cardiopulmonary resuscitation by lay people. Lancet 1967:702-4.

3. Eisenberg MS, Bergner L, Hallstrom A. Cardiac resuscitation in the community. JAMA 1979;(241):1905-7.

4. Wik L, Kramer -Johansen J, Myklebust H. Quality of cardiopulmonary resuscitation during out-of-hospital cardiac arrest. JAMA 2005;(293):299-304.

5. Rajapakse R, Noč M, Kersnik J. Public knowledge of cardiopulmonary resuscitation in Republic of Slovenia. Wien Klin Wochenschr 2010;(122):667-72

6. Owen A, Kocierz L, Aggarwal N, Hulme J. Comparison of the errors in basic life support performance after training using the 2000 and 2005 ERC guidelines. Resuscitation 2010;81(6):766-8.

7. Spooner BB, Fallaha JF, Kocierz L, Smith CM, Smith SCL, Perkins GD. An evaluation of objective feedback in basic life support (BLS) training. Resuscitation 2007;73(3):417-24.

8. Chamberlain D, Hazinski MF. Education in Resuscitation. Resuscitation 2003;59(1):11-43.

9. Parnell MM, Larsen PD. Poor quality teaching in lay person CPR courses. Resuscitation 2007;73(2):271-8.

10. Kaye W, Rallis SF, Mancini ME, Linhares KC, Angell ML, Donovan DS, et al. The problem of poor retention of cardiopulmonary resuscitation skills may lie with the instructor, not the learner or the curriculum. Resuscitation 1991;21:67-87.

11. Greif R, Egger L, Basciani RM, Lockey A, Vogt A. Emergency skill training- a randomized controlled study on the effectiveness of the 4-stage approach compared to traditional clinical teaching. Resuscitation 2010;81(12):1692-7.

12. Peyton JWR, editor. Teaching and learning in medical practice. Rickmansworth: Manticore Europe; 1998.

13. Barelli A, Scapigliati A. The four-stage approach to teaching skills: the end of a dogma? Resuscitation 2010;81(12):1607-8.

14. Bullock I. Skill acquisition in resuscitation. Resuscitation 2000;45:139-43.

15. Bullock I, Davis M, Lockey A. Kevin Mackway-Jones, editors. Pocket guide to teaching for medical instructors. 2nd ed Manchester Blackwell Publ. 2008.

16. Steinmetz J, Barnung S, Nielsen SL, Risom M, Rasmussen LS. Improved survival after an out-of-hospital cardiac arrest using new guidelines. Acta Anaesthesiol Scand 2008;52(7):908-13.

17. Olasveengen TM, Vik E, Kuzovlev A, Sunde K. Effect of implementation of new resuscitation guidelines on quality of cardiopulmonary resuscitation and survival. Resuscitation 2009;80(4):407-11.

18. Orde S, Celenza A, Pinder M. A randomised trial comparing a 4-stage to 2-stage teaching technique for laryngeal mask insertion. Resuscitation 2010;81(12):1687-91.

19. Schwerdtfeger K, Wand S, Schmid O, Roessler M, Quintel M, Leissner KB et al. A prospective, blinded evaluation of a video-assisted "4-stage approach" during undergraduate student practical skills training. BMC Med Educ 2014;14(1):104.

20. Mohamadirizi S, Fahami F, Bahadoran P, Ehsanpour S. The effect of four phase teaching method on midwifery students emotional intelligence in managing the childbirth. J Educ Health Promot 2015;4:1-5.

21. Handley AJ, Monsieurs KG, Bossaert LL. European Resuscitation Council Guidelines 2000 for Adult Basic Life Support. Resuscitation 2001;48:199-205.

22. Handley AJ. Teaching hand placement for chest compression - A simpler technique. Resuscitation 2002;53(1):29-36.

23. Jenko M, Frangež M, Manohin A. Four-stage teaching technique and chest compression performance of medical students compared to conventional technique. Croat Med J 2012;53(5):486-95.

24. Saraç L, Ok A. The effects of different instructional methods on students' acquisition and retention of cardiopulmonary resuscitation skills. Resuscitation 2010;81(5):555-61.

25. Todd KH, Braslow A, Brennan RT. Randomized, controlled trial of video self-instruction versus traditional CPR training. Ann Emerg Med 1998;31(3):364-9.

26. Pande S, Parate V, Pande S, Sukhohal N. Evaluation of retention of Knowledge and skills imparted to first year medical students through basic life support training. Advan Physiol Edu 2014;38:42-5. 